\title{
Modalidades informales de aplicación del Orden Público hacia las personas sin hogar en la zona de Río Piedras
}

Marianellie Cruz Hernández

Universidad de Puerto Rico

marianellie.cruz@upr.edu

https://orcid.org/0000-002-0986-8952 


\section{Resumen}

Las políticas de austeridad implementadas en el país resultan en mayor violación de los derechos humanos de grupos históricamente vulnerados, entre estos, las personas sin hogar. A estas, usualmente se les define como personas que carecen de un de techo y condiciones para satisfacer necesidades básicas. La población sin hogar es la mayor expresión de desigualdad, opresión, marginación, exclusión e incumplimiento de los derechos humanos. Se les criminaliza por condiciones macroestructurales, que le excluyen de participación social, económica y política. Al partir de esta visión, la persona sin hogar es vista como "criminal", por lo que se debe "controlar y castigar" como forma para mantener el orden social y la seguridad pública (Broken Windows, 1982). En Puerto Rico los códigos de orden público se utilizan como forma de control sobre el uso de los espacios públicos en las zonas urbanas. De igual manera, se han establecido modalidades informales en la intervención de estas personas, como la violencia verbal y el desecharle sus artículos personales. Todas, en reprensión por la presencia en lo público de la persona sin hogar. El siguiente trabajo se basa en la investigación: Orden Público: Experiencias de las personas sin hogar bajo la regulación de los Códigos de Orden Público en la zona de Río Piedras, defendida en mayo 2019, ante el Programa de Estudios de Honor de la Universidad de Puerto Rico, Río Piedras.

Palabras clave: persona sin hogar, código de orden público, derechos humanos, criminalización de la pobreza, espacios públicos, modalidades informales de aplicación.

Summary

The austerity policies implemented in the country have revolved in the violation of the human rights of groups historically vulnerable, among these, the homeless. They are usually defined as people who lack a roof and the conditions to satisfy their basic needs. The homeless population is the most prominent expression of inequality and oppression. They are criminalized for macrostructural conditions that exclude the person from social, economic, and political participation. Based on this vision, homeless people have been seen as "criminals" that must be "controlled and punished" as means to maintain social order and public security (Broken Windows, 1982). Thus, in Puerto Rico, the Public Order Codes are utilized to control the use of public spaces in urban areas. Likewise, informal methods of intervention have been established, like verbal violence and disposal of their belongings. All these, in repression of the presence of homeless people in public areas. The following work is based on the research: Public Order: Experiences of the homeless people under the regulation of the Public Order Codes in the Río Piedras area, defended in May 2019, at the Honor Studies Program, University of Puerto Rico, Río Piedras.

Keywords: homeless people, public order code, human rights, criminalization of poverty, public spaces, informal modality of application. 


\title{
Modalidades informales de la aplicación del Orden Público hacia personas sin hogar en la zona de Río Piedras
}

\author{
[EN] Informal modalities in the application of Public Order \\ towards homeless people in the Río Piedras area
}

\section{Marianellie Cruz Hernández}

Comúnmente se define la "deambulancia" como un problema social desde una perspectiva paternalista y punitiva, donde la persona es marcada como criminal, con uso problemático de sustancia, con alguna condición de salud mental, trabajador sexual, entre otros calificativos que se le asignan. Todos cargados de culpa hacia la persona por su situación de vida. Sin embargo, los factores macroestructurales que crean las condiciones para que una persona pueda quedarse sin hogar no se reconocen. Estos factores macroestructurales para mantener la calidad de vida incluyen situaciones socioculturales, actitudinales, socioeconómicas, y políticas imperantes que marginan e imposibilitan a la persona de tener acceso a servicios gubernamentales de educación, empleo, alimento, vivienda, y vestido, por mencionar algunos. Cuando hablamos de situaciones que afectan a la población sin hogar estamos refiriéndonos a "efectos acumulativos de la pobreza, las fluctuaciones económicas, el desempleo, las injusticias, las desigualdades sociales, los prejuicios, la violencia y el desbalance de poder" (Velázquez, 2017). Por tanto, las situaciones que afectan a esta población no pueden ser limitadas a una sola, sino que estas provienen de diversas circunstancias que han formado parte de sus experiencias a través de su vida. Como indica Rosso (2008), la "exclusión social acontece al término de trayectorias individuales a lo largo de las cuales se acumulan y se refuerzan cierto número de privaciones" (p. 2), que limitan el acceso a los servicios convirtiéndose en una constante y acumulativa privación de acceso a las estructuras económicas, sociales y políticas (Rosso, 2008). La población sin hogar no solo carece de las condiciones para satisfacer sus necesidades básicas como un techo seguro, sino que su carencia es el reflejo de la violación de sus derechos que como ciudadanos poseen, pero no le son reconocidos. Bachiller (2009) menciona que las Ilamadas "leyes anti-homeless", se crean para "evitar que los sin techo se afinquen en un espacio concreto de la ciudad” (p. 127). Puerto Rico estableció códigos de orden público a través de los municipios como una manera de regular las conductas en los espacios públicos, en especial las zonas más concurridas como las plazas, parques, urbanizaciones, avenidas aledañas a cascos de los pueblos, y otros lugares.

Según el Conteo de Personas sin Hogar del 2019, en Puerto Rico se identificaron 2,535 personas que se encuentran en situación de calle, y se añaden 2,227 personas que se encontraban en proyectos de vivienda pública durante el conteo. De estos se 
identificaron $21 \%$ como mujeres, $79 \%$ como hombres y $0 \%$ como transgénero o con otra identificación de género. Se cuantificó al $95.7 \%$ de las personas como mayores de 18 años, mientras el 4.3\% como menores de edad. Además, se identificó 698 personas sin hogar en el municipio de San Juan. Al visualizar estos números debemos comprender que no representan la realidad del total de personas en situación de calle en la actualidad. Luego del paso de los huracanes Irma y María las condiciones de pobreza y vulnerabilidad en las comunidades empobrecidas del país aumentaron, lo que añade el detrimento de los servicios públicos. Por lo que entender la magnitud de la situación de pobreza en la Isla y todos sus diversos rostros no se debe limitar a números y estadísticas, pues erróneamente se invisibiliza la situación que afecta a miles de personas en el país.

\section{Construcción del "deambulante" y políticas del Estado}

La concepción que se tiene de la persona sin hogar proviene de una construcción social desde una visión paternalista y criminalizante sobre grupos minoritarios. Marrero (2008) cita en su tesis doctoral a Rivera (1995), quien relata que durante la época colonial española se catalogaba a la persona sin hogar como "vago". Se determinaba que una persona tenía vagancia si las personas eran "capaces de trabajar, [pero] abandonaban con frecuencia su ocupación, se entretenían en agencias y tráficos viles o indecorosos, ... 0 estaban durmiendo de noche en la calle" (Marrero, 2008, p. 21). Además, la vagancia era catalogada como un delito público, se imponían multas y otros tipos de castigos. Para la década del 1930, ante la crisis económica, la población sin hogar aumentó y se reconoce como un problema social. Por tal razón, el Estado comienza a dirigir políticas a favor de la creación de entidades de caridad (Marrero, 2008).

Dado nuestra condición colonial, debemos acudir a la ley federal para poder entender la visión que desde el Estado se presenta al trabajar con la población sin hogar. La Ley Stewart B. McKinney Homeless Assistance Act de 1897, define a la persona sin hogar: como la persona que carece de una residencia nocturna fija o que su residencia nocturna principal es un refugio temporal, una institución o algún lugar que utiliza para dormir. En Puerto Rico la Ley Núm. 194 del 2016, define a la población sin hogar como la persona o familia que carece de una residencia para vivir, se encuentra en otro espacio en el cual pernocta, pero no es una residencia, o se encuentra en un albergue, entre otros aspectos. Del mismo modo, se define por la carencia de un techo fijo para residir (Ley Núm. 194, 2016).

La falta de participación en la sociedad a consecuencia de la marginación y estigmatización, constituye una violación a sus derechos fundamentales, que como ser humano y ciudadano posee. O'Neill (2009) indica que la desigualdad social se perpetúa a través de las mismas estructuras sociales que se encargan de dictaminar quienes pueden acceder a la estructura económica (p. 16). En la actualidad la visión que permea sobre la población es una que se asemeja a la visión histórica que se tenía del vago, visto como deshonesto, criminal, y peligroso, entre otros. Tal como sucedió en el siglo XX, aún el discurso de peligrosidad sobre las personas sin hogar se sostiene por medio de leyes que 
presentan a la población como la causante de problemas de orden y de convivencia en espacios públicos, y que "dañan" la imagen que se intenta presentar del espacio. Es por tal motivo que se promueve el establecimiento de medidas que permitan regular el comportamiento y uso de espacios públicos, tal como lo presentan los códigos de orden público.

La teoría Broken Windows (Wilson \& Kelling, 1982), parte de la premisa que una "venta rota" y la decadencia de los espacios son señales de que no hay vigilancia, por lo que el espacio es propicio para que se cometan delitos. Los autores afirman que las propiedades descuidadas son "presa fácil" de delincuentes, vagabundos, del tráfico de drogas, y trabajo sexual, entre otras actividades. Para los autores todos estos factores se pueden denominar como "decadencia urbana", pues "atraen" a delincuentes y brindan inseguridad a la ciudadanía "decente" (Wilson \& Kelling, 1982). Por tanto, existe la necesidad de que el Estado tome medidas de prevención en los espacios públicos, tales como formas de vigilancia, control y orden. Esto se debe a que un espacio vacío, según estos autores, da la impresión de que el área es apta para cometer delitos. Además, los "estorbos públicos" dan un mensaje de falta de protección lo que atrae la atención de criminales. Se parte de la concepción de que el criminal ya existe y los parámetros normativos tienen el efecto de desanimar sus acciones (Ruiz, 2011).

Robinson (2017) realizó un estudio en el estado de Colorado, EE. UU., con el fin de conocer el impacto de las leyes "anti-homeless" en la calidad de vida de la población. La autora indica que las leyes "anti-homeless", son el medio propuesto por el Estado para incrementar la "civilización" al fomentar en la población sin hogar un comportamiento apropiado como una forma de mejorar su calidad de vida. Además, a través de estas políticas conocidas como tough love, se ve a la persona sin hogar como una de comportamiento autodestructivo que eligió vivir en la calle negando la ayuda que le brinda el estado o la beneficencia (Robinson, 2017).

En América Latina se aborda la situación que afecta a la población sin hogar desde una perspectiva de derechos humanos, ya que la situación que afecta principalmente a la población se debe a la exclusión social y al aumento de la pobreza debido a las políticas neoliberales (Berríos Ballesteros, A., et. al. 2017). El uso de los espacios públicos se estudia desde una mirada constituida por una doble dimensión en donde el espacio público se debe abordar desde lo político y lo urbano (Berroeta y Vidal, 2012). Por medio de este análisis se valoriza lo público como un espacio democrático en el modo que se construye y se gestiona la ciudad (Berroeta y Vidal, 2012). Sin embargo, la constante privatización tiene como resultado la disolución del espacio público en la sociedad contemporánea, se sustituyen "las calles y las plazas por un conjunto de artefactos urbanos de dominio privado, y la transformación del paisaje urbano por fenómenos de homogenización de la ciudad, hipervigilancia y control espacial" (Berroeta y Vidal, 2012, p. 10). Es así como se problematiza el control de los espacios públicos como un proceso de exclusión y vigilancia 
proveniente de visiones hegemónicas. Rosso (2008), expresa que la exclusión social, además de darse en el aspecto económico, es un proceso que denota la relación entre esta y el individuo. En este aspecto vemos la dimensión política del tema, en el que el control de los espacios es problematizado desde una perspectiva de derechos ciudadanos. Por ello, se presenta el poder ciudadano como un medio de transformación critica del uso y significado de los espacios públicos (Berroeta y Muñoz, 2013).

Sin embargo, en nuestro país impera una construcción discriminatoria contra la población sin hogar que proviene de una visión prejuiciada y punitiva sobre esta, y a partir de esta ideología se sostiene que el "deambulante" es un posible "perpetrador de crímenes", "distorsionador del orden", "incivilizado", y "peligroso", entre otras concepciones. Por tal razón, es necesario establecer mecanismos de "orden", "control" o "vigilancia" para mantener el orden social y proteger a la ciudadanía. Es así como la persona sin hogar pierde su identidad ciudadana y sus derechos son constantemente violentados. Las políticas de autoridad que imperan en nuestro país hacia sectores criminalizados tienen como consecuencia que el irresponsablemente prescinda de su hacia la ciudadanía de cumplir y proteger sus derechos. Los efectos de estas políticas, además del área económica, afectan directamente la prestación de servicios gubernamentales, perjudicando a la ciudadanía. En especial, esta situación menoscaba a las poblaciones más vulneradas llevándolas a mayor necesidad, aumento del discrimen, la marginación, y la violencia que reciben de parte de las instituciones y la sociedad, y el incumplimiento de sus derechos. Estas políticas de austeridad sobre valorizan la privatización de servicios, y responsabilizan al individuo por la satisfacción de todas sus necesidades como el acceso a la vivienda, al alimento, al vestido, a los servicios médicos, entre otros. Por lo que las poblaciones pobres del país experimentan un detrimento en su calidad de vida, pues estas políticas perjudican de manera desproporcionada a los grupos más vulnerados.

\section{Códigos de Orden Público en Puerto Rico}

En 1998 en el Municipio de San Juan, bajo la administración de Sila M. Calderón, se implementó el primer Código de Orden Público en Puerto Rico como una forma de mejorar la calidad de vida de la ciudadanía (O’Neill, 2009). En el 2001 se aprobó la Ley Núm. 19, conocida como la Ley para la Adopción de los Códigos de Orden Público. A través de esta se añade el artículo 2.008 a la Ley Núm. 81 del 30 de agosto de 1991, conocida como Ley de Municipios Autónomos del Estado Libre Asociado de Puerto Rico.

Los códigos de orden público tienen como fin regular el comportamiento dentro de ciertas áreas. Según la Ley Núm. 81 de 1991, estos tienen como propósito regir espacios con "problemas de desorden o conveniencia pública" tales como: "...estorbos públicos que crean problemas de seguridad..." (p. 41). La función de los códigos es establecer "las normas de civismo y orden" para atender situaciones "causantes del deterioro en la calidad de vida" (pp. 41-42). Los municipios que implementan los códigos logran "el rescate de los espacios públicos" (p. 44), al brindar seguridad a sus ciudadanos. 
En Río Piedras se estableció el Código de Orden Público en 1998. Este define el espacio público como "...toda acera, paseo, calle, callejón, avenida, carretera, camino, zaguán, plaza, plazoleta, parque o cualquier otro similar dentro de la demarcación del Centro Urbano de Río Piedras que sea de dominio público" (p. IX-2). Entre sus artículos se prohíbe sentarse o acostarse en las aceras (Art. 9.17), pedir dinero o cualquier otro bien (Art. 9.23), y las imposiciones de multas y otros procesos legales de llevar a cabo alguna de sus prohibiciones. Las personas autorizadas a implementar el Código lo son los cuerpos de policías estatales, policías municipales y policías auxiliares, los cuales se encargan de expedir boletos y procesar los mismos ante una violación del Código (Art. 9.21; Art. 9.27; Secc. 2).

\section{Diseño Metodológico}

El trabajo de investigación se realizó bajo la metodología cualitativa con un enfoque fenomenológico. El método fenomenológico se enfoca en conocer las experiencias individuales subjetivas de cada persona participante reconociendo sus percepciones y significaciones sobre el fenómeno estudiado (Hernández, 2010). Este enfoque permitió poder comprender las experiencias de las personas sin hogar en situaciones en donde se lleva a cabo algún tipo de intervención en el que se ejercen las normas contenidas dentro del Código de Orden Público. Los objetivos de la investigación fueron: (1) recopilar experiencias de personas en situación de "calle" que han sido procesadas legalmente por violentar el Código de Orden Público en la zona de Río Piedras; (2) analizar cómo la implementación de los Códigos de Orden Público incide en la violación de los derechos humanos de las personas sin hogar; y (3) recibir las recomendaciones que propone la población sin hogar respecto a la implementación del Código de Orden Público.

Primeramente, se realizaron observaciones en el área de Río Piedras, la Plaza del Mercado, Plaza de la Convalecencia, Avenida Universidad, y las áreas aledañas del casco urbano de Río Piedras, por un periodo de dos meses, marzo-abril 2019. Durante las observaciones se recopilaron verbalizaciones de tres informantes claves respecto a la interacción de la población sin hogar en la comunidad. Luego del periodo de observación se realizaron cuatro entrevistas semiestructuradas, las cuales se utilizaron tres para propósitos de análisis en la investigación, en donde las personas entrevistadas se auto identificaron como persona sin hogar. Para el reclutamiento de participantes se acudió a varios centros de servicios para personas sin hogar en el área de Río Piedras y el Viejo San Juan, en donde se realizaron acercamientos a posibles candidatos y de forma voluntaria participaron de la entrevista. Para proteger a los participantes se llevó a cabo un proceso de Consentimiento Informado y Confidencialidad, no se identificó ningún documento con nombre u otra forma de identificación, y antes de comenzar la entrevista se realizaron unas preguntas de cernimiento para conocer si la persona se encontraba ubicada en tiempo, espacio y lugar. En las entrevistas realizadas las personas relataron distintas situaciones vividas relacionadas a la implementación del Código y violación de derechos humanos. Las entrevistas fueron transcritas al verbatim y se realizó análisis a partir de la narración de 
testimonios de las personas participantes, a través del programa cualitativo Nvivo, que permitió codificar y aglutinar verbalizaciones por categorías.

Para efectos de este escrito, se entiende que una modalidad informal de aplicación del Código de Orden Público es "todo aquel proceso en el cual se realiza una intervención hacia la persona por llevar a cabo cierta actividad dentro del espacio público la cual es considerada como que 'estorba' o 'interrumpe' la actividad social”. Estas intervenciones informales son realizadas tanto por agentes del orden público como por un ciudadano. En su mayoría son verbales, en donde se le prohíbe realizar alguna acción, se pide que se vaya del lugar, se le dicen palabras soeces y en ocasiones se agrede a la persona físicamente, como empujar. Estas intervenciones no conllevan expedir boletos o compadecer ante un tribunal como estipula el Código (Art. 9.20, 9.24; Secc. 2 y 3). Tales acciones se perciben como un proceso en el cual se vulnerabiliza a la persona ante una intervención violenta y arbitraria en donde se discrimina y menoscaba la calidad de vida de la persona.

\section{Hallazgos: Modalidad informal de implementación del Código de Orden Público en la zona de Río Piedras}

\section{Observaciones}

Las observaciones se llevaron a cabo con el fin de poder conocer la interacción de la comunidad con la población sin hogar, cómo esta participa de la vida comunitaria y su interacción con las autoridades, comerciantes y demás personas. Durante el periodo de observación se mantuvo un diario en donde se anotaron observaciones y testimonios de informantes claves.

En el proceso se visitó la estación de Policía Municipal de Río Piedras, en donde se conversó con un oficial que fue un informante clave. Durante la conversación el informante expresó que sí se aplica el Código, tanto a comerciantes como a civiles en el área, pero dado a que es un proceso extenso y burocrático muchas veces no se concretiza la de una multa ni el proceso legal en su totalidad. El oficial explicó que, al llegar un caso al tribunal con una persona sin hogar, si durante el proceso se le permite irse, luego no hay forma de encontrar a la persona por la falta de una dirección u otro contacto, por lo que actualmente no se realiza el proceso legal de aplicar una multa. Asimismo, según expresó el informante, actualmente no se llevan casos hasta un tribunal para la aplicación de delito menos grave como establece el Código de Orden Público, Río Piedras. Aunque no exista un memorando que releve a las autoridades de aplicar el Código de Orden Público, como expresó el informante clave, estos no adjudican las multas por la incapacidad de poder continuar el proceso. También explicó, que en la actualidad la mayoría de las acciones que se toman es para forzar a la persona a moverse del espacio o se le lleva a un centro de servicio para la población sin hogar. Además, durante la conversación se dialogó sobre la interacción de la población sin hogar con la comunidad y con los policías, a lo que el informante clave expresó que las personas sin hogar son "agresivos con la policía", pues en ocasiones "compañeros los han tratado mal y abusado", así que, "ya piensan que todos le vamos a hacer lo mismo". 
También, se le preguntó qué servicios le dan a la población cuando se les detienen, a lo que contestó que se llevan a centros para que reciban servicios, como albergues.

Del mismo modo, se dialogó con un segundo informante clave en la zona del Viejo San Juan. Este relató una experiencia sobre acciones tomadas por el Municipio de San Juan hacia las personas sin hogar. Mencionó que en ocasiones los empleados municipales van a los espacios en donde las personas en situación de calle tienen sus pertenencias y comienza un "proceso de limpieza", que consiste en botar las pertenencias de las personas que se encuentran en el área, mayormente en momentos de actividades en el pueblo.

A través del proceso de observación se visualizó la interacción de las personas sin hogar dentro del contexto del área de Río Piedras. De igual forma, se estudió el efecto de los procesos de vigilancia y control que tienen sobre la población sin hogar. El 5 de marzo de 2019, mientras se realizaba una observación de campo en la Plaza del Mercado, se conversó con un comerciante en la plaza sobre la población sin hogar. Esta persona expresó que las personas sin hogar solo "compran un café y se van, no están mucho rato aqui", pues no se les permite estar mucho tiempo. En ese momento la persona con quien se conversaba señaló la presencia de una persona sin hogar en el área, quien solicita dinero o comida a quienes se encontraban cerca. Ante esta situación la guardia privada, que se encontraba trabajando en el lugar, se mantuvo cerca de la persona sin hogar hasta que esta salió de las facilidades de la Plaza del Mercado.

Este proceso de observación previo a la realización de entrevistas permitió entender mejor la interacción de la población sin hogar dentro del espacio público, así como los efectos de los procesos de vigilancia y control que se establecen por medio del Código de Orden Público. Así, se pudo observar interacción de la población en la comunidad y cómo estos procesos de vigilancia ocasionan que se tenga una concepción del espacio público como uno exclusivo, en el cual la población sin hogar es excluida. Es de esta manera, como se concibe el ideal de poder para marginar y segregar de forma indiscriminada a las personas en situación de calle de los espacios con el pretexto de asegurar un espacio seguro y de armonía para quienes se consideran personas con ciudadanía.

\section{Entrevistas}

Entre los resultados obtenidos de las entrevistas dos participantes verbalizaron tener una experiencia en donde se realizó una aplicación informal del Código de Orden Público de Río Piedras. Como se mencionó anteriormente, una aplicación informal es cualquier intervención hacia la persona sin hogar por realizar una actividad en el espacio público, la cual es considerada como que "estorba" o "interrumpe" la actividad social. Las mismas resultan en una acción discriminatoria que violenta los derechos humanos y civiles ubicando a la persona en una posición de mayor vulnerabilidad.

Según el Código de Orden Público las personas facultadas para emplear el mismo lo son: los cuerpos de policías estatales, los policías municipales y los policías auxiliares (Art.

9 
9.21; Art. 9.27; Secc. 2). Sin embargo, algunas de las verbalizaciones realizadas por las personas que participaron de la investigación reflejan, que tanto oficiales como civiles realizan intervenciones informales con la población sin hogar. Algunos de estos testimonios son:

... sé de dos deambulantes que le han da'o ... una vez le dieron a uno por estar durmiendo aquí en una tienda que no voy a decir, se quedó durmiendo ahí y por la mañana, ... aaa las seis vinieron y le dieron pata pa' que se fuera, porque tenían que abrir el negocio (Participante \#3, en entrevista, marzo 2019).

... los otros días me paso que estoy del lado de la acera de allá, y tenía hambre y le dije a un cliente a ver si me podía comprar algo de comer, porque yo como tal no pido chavos, que si me podía comprar algo porque tenía hambre y salió el gerente a decirme que me tenía que mover que no podía pedir ahí. Yo le pregunte por qué yo no podía pedir, ... y me dice porque estorbas. ... yo estoy fuera del establecimiento, yo estoy en la acera y si le estoy pidiendo a un cliente tuyo ... Así que, si tú quieres llamar a la policía las veces que te dé la gana porque yo no me voy a mover, yo me voy a quedar aquí. (Participante \#1, en entrevista, marzo 2019).

Pero, ¿cómo yo me siento personalmente? Me siento... yo entiendo que es una violación de los derechos, es un abuso, un abuso de poder, un abuso humano.... Humillante. Porque ellos empiezan a hablarle: ... mira te tienes que ir pa' aquí pa' allá y casi siempre eso se eleva, y el deambulante le dice algo ta'[sic] bien me voy, ... no, no me saque de aquí, o o o vete pal' Caribe Hilton y ahí e'ploto la bomba y entonces el otro empieza a humillar y habla malo o le dice que tiene que va a llamar a los guardias. Así son las intervenciones, por lo general, empiezan bien y terminan [elevando la mano] ahora si el deambulante le sale de tras pa'lante olvídate que eso e'plotará... (Participante \#3, en entrevista, marzo 2019).

La calle es una experiencia de dos mundos. Está el mundo de los civilizados y el mundo de la calle. Cuando tú vives en la calle es duro y este otro mundo, el de acá, pone una pared que no te permite entrar... (Participante \#4, en entrevista, marzo 2019).

Como mencionó un oficial de policía como informante clave, en la actualidad el proceso de aplicación del Código de Orden Público no se realiza según lo establecido en el mismo. Sin embargo, se realiza una aplicación informal, como lo evidencian los testimonios de las personas informantes claves y, sobre todo, las expresiones de las personas participantes quienes viven día a día este tipo de situaciones. Para la población sin hogar el área pública se convierte es un espacio en donde desarrollar su vida en interacción, intercambio y afiliación con otras personas y con el lugar. Berroeta y Muñoz (2013) explican que "la calle es para este grupo mucho más que un medio ambiente o un contexto, ella constituye un espacio simbólico y de representación que opera como referente de 
identidad" (p. 4). Estas verbalizaciones por las personas participantes demuestran que sus experiencias de vivir en la calle han significado ser "un proceso gradual y permanente de exclusión" (p. 12), en el cual se les obliga a una movilización forzada y constante exclusión de la actividad social, laboral y política, entre otras, en el espacio donde se encuentra. Como relata la persona Participante \#3, estas experiencias además de vivirse individualmente son acciones que se experimentan colectivamente. Esto lo podemos ver cuando la persona verbaliza la experiencia vivida por otra persona sin hogar, la cual es agredida por un tercero. Esta acción fue identificada como una situación a la que todos están expuestos a diario y que ponen en riesgo su vida y establecimiento en un lugar dado. Además, como expresa la persona Participante \#4, la población sin hogar se percibe segregada de la sociedad en general, lo que a su vez incide en una autoexclusión, que vulnera y conduce a un detrimento en la calidad de vida de la población sin hogar ante la imposibilidad de poder reintegrase en los procesos comunitarios, económicos, políticos, y otros.

Estas intervenciones, a pesar de no llevarse a cabo de acuerdo con el proceso establecido por el Código, si provienen de su predominio en la zona y de una visión hegemónica del control social y del llamado orden público que se establece en el área. Por tanto, nos referimos a una situación que va más allá de una implementación informal de un Código. Estamos ante una situación en la cual las ordenanzas gubernamentales y municipales son utilizadas como un medio para violentar y menoscabar la vida y derechos de los ciudadanos. Esto supone un acto de violencia hacia la ciudadanía, en donde sus derechos humanos y civiles no son respetados ni llevados a su cumplimiento y satisfacción.

En la medida que se realiza un acercamiento a la persona por llevar a cabo una actividad en el área partiendo de que su presencia es un estorbo, perturbación o molestia, se ejerce un acto de violencia contra la persona. Como señalan las personas que participaron, las intervenciones que se realizaron en su mayoría fueron por aparente perturbación en algún negocio o por estar en un espacio público en donde fueron intervenidos por agentes de seguridad o por civiles de forma verbalmente violenta. En sus expresiones se evidencia cómo en la mayoría de las ocasiones las intervenciones con la población se realizan en forma violenta, sea de forma verbal, física o actitudinal hacia la persona. Por ello, podemos decir que a pesar de que el Código no sea aplicado en su totalidad por las autoridades pertinentes, esto no implica que este no se aplique con una modalidad informal. Ante ello, estamos ante una situación mayor en la cual el Código se aplica en una modalidad informal, en la medida que las actividades realizadas por las personas sin hogar se observan como "perturbadoras del orden social" y su presencia supone un "estorbo" en los espacios públicos. Esta implementación informal continúa perpetuando la visión punitiva y criminalizante, así como mantener el "control" de los espacios y la vida. Además, implica la violación de derechos humanos y civiles de la población sin hogar. Se violentan derechos tales como: la igualdad del ser humano, libertad de expresión, el discrimen, la dignidad del ser humano, la protección de ley contra ataques a su honra, entre otros que contempla la Constitución de Puerto Rico y la Declaración Universal de Derechos Humanos. 
Como menciona el segundo informante, durante el periodo de observación, se realiza un "proceso de limpieza" en donde se botan pertenencias de las personas, principalmente en momentos de actividades en los espacios públicos. Estas medidas tienen como resultado presentar una imagen de la ciudad libre de "estorbos públicos". Sin embargo, su resultado es la violación de derechos, invisibilización, transgresión y marginación de la población sin hogar. Este tipo de intervención es respaldada por una visión prejuiciada en donde la persona sin hogar se concibe como un posible "perpetrador de crímenes" y "distorsionador del orden y civilidad". Como forma de asegurar la paz y disfrute del espacio por parte de la ciudadanía se realizan estos "procesos de limpieza" tan necesarios para mantener una imagen irreal de la situación social, económica y política de la ciudad y del país.

Este tipo de intervención representa una violación a los derechos en la medida que se intenta invisibilizar y minimizar a la persona, se violenta su dignidad, su libre determinación, y se le somete a un trato cruel. Bachiller (2009) indica que la restricción del uso del espacio público "implican una forma de exclusión que las condena a elegir entre dos opciones igualmente angustiantes: la reclusión en las instituciones diseñadas para estas poblaciones o un transitar incesante" (p. 127). Con estas medidas se obliga a la población a una movilidad forzada negando el uso del espacio y, por tanto, de tener un lugar fijo, se le niega el ser, el vivir y la estabilidad de poder estar en cierta zona escogida por la persona de forma autónoma. Por lo tanto, hablar de las implicaciones de los códigos de orden público en la vida de las personas sin hogar va más allá de simplemente no permitir ciertas actividades. Implica que estas medidas prohíben al ser humano su libertad y búsqueda de medios para vivir, es decir se violentan en su totalidad sus derechos. En el caso de la población sin hogar este tipo de intervención vulnerabiliza a la persona ante un trato cruel, tanto verbal, físico y hasta psicológico. De igual forma, obliga a la persona a renunciar a su autodeterminación al impedir realizar actividades y al obligarla a desplazarse de la zona. Por tanto, la violación de derechos no se da solo por la formalidad de un proceso legal en contra de la persona, sino que la violación surge de los motivos que generan la intervención y cómo se lleva a cabo el trato e intervención.

\section{Reflexión desde el Trabajo Social}

Cuando hablamos de los códigos de orden público debemos ver que más allá de una forma de establecer un orden social dentro del espacio público es una forma de establecer control de los espacios, determinando quién es apto para permanecer en el área y formar parte de la actividad social. De esta forma, se puede ver cómo la lucha entre clases y grupos se establece manteniendo un proceso de estigmatización sobre grupos oprimidos, en este caso la población sin hogar. Dado a que la zona ha sido invadida por un grupo de personas "no gratas" es deber del orden público recuperar ese espacio para el disfrute de la ciudadanía (Bachiller, 2009). Esto ejerce sobre la población una movilización forzada, que a su vez limita su estabilidad en un área determinada y por consiguiente los servicios que voluntariamente busque. La población sin hogar es "descartada" de la sociedad y los 
espacios, y se convierten en víctimas de la invisibilidad, la marginación, el desprecio y de la injusticia social.

El hecho de que en la actualidad no se someta a la persona a pasar por un proceso legal en su contra por violentar el Código, no significa que estas modalidades informales de aplicación afecten su vida. La violación de derechos proviene de las visiones punitivas que impulsaron la creación de un Código de Orden Público que promueve un proceso de "limpieza y cuidado de los espacios", pero que su fin es mantener control de la vida en la ciudad. Es por esta razón que podemos observar una aplicación informal del código que le ha dado autoridad a toda persona, incluso civiles, a ejercer cierto dominio sobre el espacio, aun cuando esto implique violentar los derechos humanos. Dado a que la población sin hogar es anulada y violentada de sus derechos humanos y civiles, el espacio público es un lugar en el cual no se le permite su presencia, pues este constituye un espacio para el uso y disfrute de "ciudadanos". Cuando se puede observar la aplicación de una medida legal de forma arbitraria, tanto por agentes como por civiles, nos cuestionamos la validez de esta y su función. Estas medidas se crean con el aparente interés de garantizar un espacio público para el disfrute de los ciudadanos, sin embargo, a la población sin hogar, entre las muchas cosas de las que han sido privadas, se encuentra su carácter ciudadano. Por tal motivo, es que se concibe a esta población como separada de la sociedad, por lo que es marginada, discriminada, oprimida y vulnerada. Es así como las políticas y de control y vigilancia afectan en mayor intensidad a la población en situación de calle, al violentar sus derechos y limitar los espacios en donde pueden encontrarse libremente y satisfacer sus necesidades.

Ante la creciente privatización se pierde el espacio público en donde el dominio privado supone una transformación del "paisaje urbano por fenómenos de homogenización de la ciudad, hipervigilancia y control espacial” (Berroeta y Vidal, 2012, p. 10). Esto hace cuestionar la transformación del espacio público democrático de ocio y disfrute colectivo a uno de control que presume la aplicación de los códigos de orden público. Es por ello que, desde un análisis enfocado en el desarrollo humano y sus derechos, se concibe el espacio público como un medio de creación, acción y desarrollo político de forma colectiva. En estos espacios las personas que viven las situaciones a diario son actores del proceso, pues al final son ellos y ellas quienes mejor conocen su situación, qué les afecta y qué herramientas necesitan para su vida.

Disminuir el efecto de las intervenciones informales requiere minimizar la violación sistematizada de los derechos que se cometen en detrimento del ser humano. Es necesario plantearnos que el acceso a la justicia es el acceso a medios que garanticen y permitan que toda persona pueda mantener una vida digna y segura, así como sus derechos sean respetados y cumplidos. La modalidad informal de aplicación del Código de Orden Público representa una violación a los derechos de la persona. Como profesionales del Trabajo Social debemos cuestionar las medidas establecidas por el Estado y la visión que respalda para poder ejercer un verdadero trabajo transformador. Se debe cuestionar esta movilidad 
forzada, dado que los servicios que se ofrecen desde las agencias deben ser solicitadas voluntariamente y no de forma obligatoria por medidas de limpieza que realiza el estado hacia la población con el fin de impulsar una imagen de orden y belleza en la ciudad. De igual forma, estas modalidades informales presumen otorgar al y civiles la autoridad de discriminar y oprimir, ejerciendo violencia verbal y hasta física sobre las personas que se encuentran en situación de calle.

Definitivamente, no podemos hablar de esta situación que enfrenta la población sin hogar sin señalar nuestra situación colonial y crisis de austeridad que vivimos como país. Las políticas impuestas sobre la sociedad han repercutido en el detrimento de la calidad de los servicios, por lo cual las necesidades de la población han aumentado. La imposición de una Junta de Control Fiscal evidencia nuestra condición colonial, la cual imposibilita un desarrollo sostenible y autóctono que propicie los medios para el crecimiento y fortalecimiento de una economía propia. Esto, junto con la corrupción y desmantelamiento de los servicios públicos, implica que las condiciones de vida principalmente de los trabajadores, retirados y de los sectores vulnerables se vean cada vez más amenazados, entre ellos la población sin hogar. Es por esta razón que los servicios gubernamentales de servicio a las personas en situación de calle han disminuido en cantidad y calidad, al ser en muchos momentos relegado al sector privado, como fundaciones o iniciativas comunitarias. Si bien muchas iniciativas privadas aportan al establecimiento de servicios para la población sin hogar, no debemos desviar ni liberar la responsabilidad primaria que tiene el Estado de velar, cumplir y satisfacer los derechos humanos y civiles de toda persona.

En estos momentos de crisis de austeridad y colonialismo que vivimos en el país debemos posicionarnos en favor de los derechos de la población sin hogar de forma que tengan control de su destino. Es por que el Trabajo Social es una profesión que aspira a ser una de transformación y emancipación en donde la persona tome autonomía sobre su vida. Como una profesión diversa, amplia, de acción política y social, entendemos que nuestras acciones inciden en la vida de las personas y de la sociedad. Abordar la desigualdad desde un enfoque de acción política es analizar la misma desde una perspectiva de desarrollo humano en donde el efecto de la desigualdad no es solo económico, sino también en sus esferas de la salud, la educación, la alimentación, la vivienda, la prestación de servicios y el respeto a los derechos humanos.

Analizar la desigualdad desde el desarrollo humano es problematizar las desigualdades no solo en su efecto económico, sino también al abordar los problemas en las esferas de salud, educación, alimentación, vivienda, prestación de servicios, y respeto a los derechos humanos. Como profesionales del Trabajo Social tenemos un compromiso de afirmación y respeto hacia los derechos humanos, así como fomentar que la persona pueda aceptarse a sí misma, y reclamar y exigir sus derechos humanos. Por tal razón, debemos reconceptualizar la visión del acceso a la justicia como el acceso y disfrute de la totalidad 
de derechos humanos y civiles y, por consiguiente, a los servicios necesarios para, más allá de suplir sus necesidades básicas, tener calidad de vida digna. 


\section{Referencias}

Bachiller, S. (2009). Significados del espacio público y exclusión de las personas sin hogar como un proceso de movilidad forzada. Revista Española de Investigaciones Sociológicas (REIS), 128(1), 125-137. Recuperado el 10 de agosto de 2018 de https://www.ingentaconnect.com/content/cis/reis/2009/00000128/00000001/a rt00005\#

Berríos Ballesteros, A., Bonilla Algovia, E., Suárez Rodríguez, A. C., Rodríguez, K., \& Vázquez Cabrera, J.J. (2017). Personas en situación sin hogar en León (Nicaraguas): definición, número, características y necesidades básicas. Recuperado el 8 de agosto de 2020 de https://www.google.com/url?sa=t\&source=web\&rct=j\&url=https://dialnet.unirioja.e s/servlet/articulo\%3Fcodigo\%3D6088126\&ved=2ahUKEwj_p6ic99_rAhUjWN8KHT bFAhoQFjAAegQIAxAB\&usg=AOvVaw36fyC9JiOQ01G1Bkk63Enk

Berroeta Torres, Héctor, \& Vidal Moranta, Tomeu (2012). La noción de espacio público y la configuración de la ciudad: fundamentos para los relatos de pérdida, civilidad y disputa. POLIS, Revista Latinoamericana, 11(31). Recuperado el 10 de agosto de 2020 de https://www.redalyc.org/articulo.oa?id=305/30523346004

Berroeta, Héctor, \& Muñoz, María Isabel (2013). Usos y significados del espacio público en personas en situación de calle. Un estudio en Valparaíso y Viña del Mar. Revista de Psicología, 22(2), 3-17. Recuperado el 10 de agosto de 2020 de https://www.redalyc.org/articulo.oa?id=264/26430690002

Congreso de los Estados Unidos. (1987). Ley 100-77 Law McKinney. Vento Homeless Assistance Act.

Estado Libre Asociado de Puerto Rico. (2016). Ley 194, Ley Para enmendar la Ley Núm. 130 de 2007. Ley para crea el Concilio Multisectorial en Apoyo a la Población sin Hogar.

Estado Libre Asociado de Puerto Rico. (1991). Ley 81, Ley de Municipios Autónomos del Estado Libre Asociado de Puerto Rico de 1991.

Hernández Sampieri, R., Fernández, C., \& Baptista, P. (2010). Metodología de la Investigación. ( $5^{\mathrm{a}}$ ed.) Editorial Mc Graw Hill.

Legislatura Municipal de San Juan. Código de Orden Público del Centro Urbano de Río Piedras.

Marrero Teruel, R. (2008). Las personas sin hogar: confinados/as de la calle, la construcción dela población sin hogar y sus implicaciones para la política pública. [Disertación Doctoral]. Universidad de Puerto Rico. Recuperado el 2 de agosto de 
2018 de https://legislaturasanjuan.pr/biblioteca/codigos-y-reglamentos/codigosde-ordenpublico/8501-codigo-de-orden-publico-de-rio-piedras/file

O’Neill, J. Z. (2009). Análisis de la política pública: la aplicación de la política pública del Código de Orden Público en el Municipio de San Juan y la criminalización de la de ambulancia. [Tesis M.P.A.]. Universidad de Puerto Rico.

Organización de las Naciones Unidas. (1948). Declaración Universal de los Derechos humanos. Robinson, T. (2017). No Right to Rest: Police Enforcement Patterns and Quality of Life Consequences of the Criminalization of Homelessness. Urban Affairs Review. https://doi.org/10.1177/1078087417690833

Rosso, M.C (2008). Los deambulantes: La representación social de los deambulantes acerca de su situación de exclusión social en la ciudad de La Plata en el año 2007. $\checkmark$ Jornadas de Sociología de la UNLP. En Memoria Académica. Recuperado el 9 de agosto 2020 de http://www.memoria.fahce.unlp.edu.ar/trab_eventos/ev.6390/ev.6390.pdf

Ruiz Vásquez, J. C. (2011). La película de la seguridad: lecciones internacionales. Papel Político,16(2). Recuperado el 25 de septiembre de 2018 de http://www.redalyc.org/html/777/77722772012/

Velázquez Morales, F. (2017). El rostro de la deambulancia en Puerto Rico: estudio crítico del discurso de los estudiantes de Trabajo Social. [Disertación Doctoral]. Universidad Complutense de Madrid.

Wilson, James Q. y Kelling, George L. (1982). Broken Windows. The police and neighborhood safety. The Atlantic Monthly. Recuperado el 18 de septiembre de 2018 de https://www.theatlantic.com/magazine/archive/1982/03/brokenwindows/304465/ 